\title{
Christian Anti-Psychology and the Scientific Method
}

\author{
JAMES D. FOSTER \\ George Fox College \\ Newberg, Oregon \\ MARK F. LEDBETTER \\ Western Conservative Baptist Seminary \\ Portland, Oregon
}

Christians are becoming increasingly vocal in their criticism of scientific psychology. In their criticisms Christian anti-psychologists have devalued knowledge gained through research and suggested both that the scientific method is inappropriate for studying human behavior and that the deception inherent in psychological research is immoral. This article examines these concems and argues that the more subjective alternatives suggested by the critics of psychology suffer from many of the same limitations as scientific psychology and that taking such an approach would amount to substituting uncontrolled error for controlled error and uncontrolled deception for controlled deception.

Throughout the short history of modern psychology, the Christian community has viewed both the methods and results of psychology with suspicion. While this suspicion has a broad base, many concerns can be traced to psychology's approach to knowledge through the use of the scientific method. When psychology emerged from philosophy as a separate discipline, its distinctiveness was in its adoption of scientific methodology from the natural sciences. The issues of philosophical psychology were reframed to conform to, and were explained within the confines of, the modern scientific model. Empiricism, determinism, relativism, and reductionism became the major tenets of psychology. This reframing meant that certain questions, not suitable for scientific investigation, could not be asked and others could not be answered satisfactorily. For the most part, however, use of the scientific method has provided us with a

Requests for reprints should be sent to James $D$. Foster, PhD, Department of Psychology, George Fox College, Newberg, Oregon 97132. unique perspective on human behavior that cannot be duplicated by other disciplines using different methodologies.

Some Christians, however, are uncomfortable with psychology in its empirical form. For example, a recent issue of the BibleScience Newsletter, normally dedicated to promoting creationism, devoted an entire issue to critiquing psychology. Articles from this issue included "The Failure of Modern Psychology" (Thorn, 1986), "Why Bother With Psychology?" (Bartz, 1986), and "Sensible Psychology: How Creation Makes the Difference" (Pearcy, 1986). These articles warn that modern psychology is spiritually dangerous, that psychology is not a science, and that psychology is invalid since it relies on ways of knowing other than through authority (i.e., the Bible). But when Christians, or others, criticize psychology's reliance on empirical methods, they are attacking its distinctiveness and what has made it a valuable contributor to human understanding. Further, in arguing for the use of nonempirical methods, the critics of psychology 
overlook the weaknesses in the alternative methods that they advocate. This article examines the current criticism of scientific psychology and the alternatives implied or suggested by the critics.

\section{Conflicting Paths to Knowledge}

Part of the conflict between Christian antipsychologists and psychology is over the proper path to knowledge. There is, of course, more than one way to knowledge and each path to knowledge has its strengths and limits. Perhaps the oldest approach is a reliance on "authority." In this view, answers to mysteries can be obtained by reference to recognized authorities. The Bible is such an authority to Christians because of its revelatory nature. A second path to knowledge is through "intuition and subjective experience." An example of this would be creative writers and artists who represent a view of reality based on their personal experiences and on their interpretation of that experience. The wide variety in the experiences of writers provides us with varied and interesting interpretations of the world. A third path to knowledge is through "logic and rational thought" Rationalism relies on reason to establish truth. A fourth path to knowledge is through "logical positivism," which rejects intuition as a reliable source of knowledge and relies instead on observation. While logic and reason are a valuable part of the process, confirmation must ultimately come through observation and experimentation.

Logical positivism serves as the philosophical foundation for a psychology which emphasizes observation, measurement, and experimentation (i.e., empiricism) as necessary components in the search for knowledge. Christianity, on the other hand, emphasizes reliance on revelation as an authority and values faith and subjective experiences. It is not surprising, then, that a religion that emphasizes faith and belief in forces which cannot be seen, measured, or quantified, has difficulty accepting a methodology that emphasizes that which can be seen, measured, and quantified.
This conflict between Christianity's approach to knowledge and other approaches can, at times, take on tones of anti-intellectualism. For example, Leahey (1980) in his history of psychology notes that some Christians have always rejected the role of reason in seeking truth, and writes:

It should be pointed out that not all Christian thinkers in whatever time have accepted the rule of reason in seeking Godly truth. Augustine had to struggle against ideas of those like Tertullian (160-230) who rejected the classical philosophers. St. Bernard (1091-1153) decried excessive "curiosity" about Christian beliefs. Savonarola (14521498) burnt heretical books. . . . All these people emphasized the mystical aspects ... the immediate inward confrontation of man with God. . . . They rejected reason as at best unnecessary, at worst heretical. (p. 58)

This concern over the proper path to knowledge continues today and can be seen in the attitudes of some Christians. Tim LaHaye (1980) writes, "Only two lines of reasoning permeate all of literature: biblical revelation (the wisdom of God) and the wisdom of man" (p. 27). LaHaye believes that man's use of his reasoning abilities has had an evil influence in the development of western civilization and is pervasive today. Similarly, William Kirk Kilpatrick (1983), in expressing his belief that psychology is a destructive force, writes, "You needn't be a scholar to sense this. In fact, scholarship is often a hindrance to understanding what is really happening" ( $p$. 30). Like St. Bernard, LaHaye, Kilpatrick, and other Christian critics of psychology seem to decry excessive curiosity, at least when applied to human behavior.

If reason is not an acceptable source for reliable knowledge, then knowledge gained through approaches that use reason are not to be trusted. To deal with such a weakness in psychology, some Christian critics emphasize the spiritual over the psychological. For example, Billheimer (1977) writes:

Except where there is organic difficulty, the root of all conflicts in the home is not mental, but spiritual. Psychology and psychiatry are usually totally irrelevant... Many spiritually disceming persons are quite convinced that psychiatry is Satan's substitute for the Biblical remedy for disturbed relations. (p. 89)

Others would argue that psychology isn't merely "irrelevant" but rather is the cause of 
many of society's problems. For example, Paul Vitz (1977) argues that psychology is "deeply anti-Christian" and has been for years "destroying individuals, families, and communities" because of its "destructive logic" (p. 10). Even attempts at Christian psychologies are accused of diluting the "milk of the word" (Smith, 1975). Others, focusing on different paths to knowledge put forth by psychology and theology, have argued that when empirical psychology and the Bible contradict, the authority of the Bible must take precedence (Crabb, 1981). While it is beyond the scope of this article to specifically deal with the question of biblical authority (see Breshears \& Larzelere, 1981), it does appear that among Christians and Christian psychologists there exists a widespread, broadly based anti-psychology movement.

\section{Christian Anti-Psychology and Non-Empirical Ways of Knowing}

Two Christian critics of psychology, William Kirk Kilpatrick $(1983,1985)$ and Mary Stewart Van Leeuwen $(1982,1985)$ have emerged in recent years as particularly visible and have the distinction of making their living in psychology while at the same time critiquing it. While Kilpatrick and Van Leeuwen criticize psychology from different perspectives, underlying both sets of concerns is a discomfort with psychology's empirical path to knowledge and a belief that psychologists overlook important intuitive sources of knowledge in their quest for objectivity.

An example of this emphasis on intuition and devaluing of empiricism can be seen in Kilpatrick's (1983) book, Psychological Seduction. Here Kilpatrick accuses psychology of not only leading Christians away from their faith but that even non-Christians have "been led away from ... [their] better instincts and common sense" (p. 26). Kilpatrick highly values "common sense" in his book, but does not value scientific research. For example, Kilpatrick attempts to make the point that there is reason to "doubt the competence of psychological helpers" (p. 28). Kilpatrick first makes his point by uncritically listing a string of unreferenced studies which indicate that nonintervention is as useful as psychotherapeutic intervention, and second by pointing out that the field of psychology has grown at the same time as the number of psychological problems in our society. Although Kilpatrick does not cite any numbers to support his argument, he nevertheless is implying a statistical case against psychology. He then goes further, though, and devalues his own empirical case, writing:

I don't want to leave the impression that there is conclusive proof of psychology's failure. Statistical evidence always has its problems. For instance, the fact that two things occur together is no proof that one causes the other.... The fact that the growth of psychology corresponds to growing social prolems could conceivably be only a coincidence. (p. 33)

Since Kilpatrick (1983) is clearly devaluing research here, how then does he expect the reader to determine the fitness of psychology? Ideas are to be checked against "common sense." Kilpatrick writes:

Take, for example, two of the most tenaciously held claims of popular psychology: the idea that role-playing stunts our self-expression and the idea that venting anger is good for us. If you subject either of these notions to a moment's reflection, you will see there are a great many instances where the reverse is true. (p. 34)

While claiming that two of psychology's most tenaciously held claims are that "role playing stunts our self-expression" and "venting anger is good for us" is wildly misrepresentative, our main interest here is his belief that a "moment's reflection" will invalidate psychological research. Christian anti-psychologists often seem to value intuitive processes like "reflection" and "common sense" above psychology's empirical tradition of systematic research. But they fail to see that what is "common sense" to one person may not be to another. It is common sense that, in dating, "birds of a feather flock together." In other words, the more similar people are, the more they will be attracted to each other. It is also common sense that "opposites attract." Conflicts such as these arise because a person's common sense is actually a collection of their personal experiences and beliefs and may have little or nothing in common with another person's experiences and beliefs. 
Since Kilpatrick (1983) makes it clear that he does not value "scholarship" and empirical ways of knowing, and that he believes psychology is replacing religion, you might expect that he would make his case against psychology on the basis of Scripture and reference to authority, as many Christian critics do. Kilpatrick, however, prefers intuition and subjective experience to authority, and supports his case through personal experience, anecdotes, and even the literary characters of creative writers. Kilpatrick opens his book with an anecdote based on his personal experience, and these kinds of examples populate his entire book. At one point he suggests that psychology has created a "climate of unrelenting seriousness" (p. 64). Then, after pointing out that "I cannot prove statistically what I am about to say" (which is a peculiar comment since he does not value statistics), he suggests that this "unrelenting seriousness" has produced a social climate which "does not allow much room for spirited eccentricity, for the larger-than-life character represented in literature by Sir John Falstaff or Samuel Pickwick" (p. 65). Kilpatrick's reference to the "climate of unrelenting seriousness" in the world illustrates another part of the problem with intuitive ways of knowing. We regret that Kilpatrick perceives the world as being unrelentingly serious, but since our subjective worlds are not, we believe he is overgeneralizing. In fact, it is possible that Kilpatrick is the only person in existence with this feeling of unrelenting seriousness. His subjective experience tells him that his world perception is real but it cannot tell him what others are experiencing. Further, his reasoning that since characters like John Falstaff don't exist in society, psychology must be preventing it, may make intuitive sense but sounds irrational and is a good argument for the use of logic and empirical methods.

Kilpatrick's (1983) case against empirical psychology, then, is primarily based on intuition and is made up of selective "statistics"-that are largely unreported, unreferenced, and not respected by the author himselfanecdotes, personal experience, and reference to creative writers and their literary characters. While it is an interesting collection of material, it represents only one person's private world view. Empirical research, on the other hand, requires public verifiability to avoid this kind of subjectivism and overgeneralization.

Like Kilpatrick (1983), Christian psychology critic Mary Stewart Van Leeuwen (1982, 1985) values subjective experience over the empiricism of psychology and would replace or at least modify the methods of psychology to make more room for intuition and subjective experience. Van Leeuwen's criticisms, however, are better supported and more specific than Kilpatrick's, and more clearly focus on psychology's methodology.

Van Leeuwen (1982) likens modern psychology to a "sorcerer's apprentice," a reference to psychology's patterning of itself after the natural sciences. In her attacks on the methodology of psychology, she focuses on experimental psychology and its reliance on controlled conditions. Van Leeuwen argues that (a) psychology's experimental methodology has shown itself to be unsuccessful in achieving what a science of psychology aims to achieve, and (b) the moral cost of psychological experimentation is unacceptably high. We will return later to her concern over the morality of psychological research and focus at this point on her concern over psychology's use of the experimental method.

Among other criticisms, Van Leeuwen (1982) argues that the experimental method is inappropriate for psychological research since humans exhibit reflexivity in experiments when they know the purpose of the experiments, that experimental results are not exportable since they are situation-specific, and that the adoption of the methods of the natural sciences has led psychology to ignore "many specifically human concerns" (p. 305). While it is beyond the scope of this article to respond to all of her charges (see Foster, 1984; Yeats, 1984), it is interesting to note that, like Kilpatrick (1983), Van Leeuwen uses anecdotes and personal experience in a way that goes beyond simple illustration and shows her preference for this particular way of knowing.

Van Leeuwen (1982) periodically punc- 
tuates her arguments with stories from her personal experience and the experiences of others. While it is common to illustrate with stories, Van Leeuwen and Kilpatrick (1983) go beyond this and seem to build their cases on such experiences and "common sense." For example, in arguing that psychology's use of deception has created a climate of suspicion in the country, Van Leeuwen uses the story of a student who bursts into her office after having just found a person lying in a pool of blood. In explaining why he hesitated in coming to call for help, he stated, "I thought it was just another psychology experiment" (p. 303). The ironic thing about this example is that it follows a lengthy chastisement of psychology for overgeneralizing research results, and Van Leeuwen fails to point out that her concerns about overgeneralization apply whether the incident in question is part of a psychology experiment or part of her personal experience. Instead, Van Leeuwen labels this the "boy who cried wolf effect" (p. 303) and asserts that psychology's practices have had a deleterious effect on helping behavior.

The tendency of people to be drawn to personal experience and vivid stories is understandable. Professors frequently run into this in their classroom experiences. Whenever presenting normative data it is inevitable that some student will raise their hand and point out that they "know someone" who is not like that. What they fail to see is that this personal experience adds only one to the sample. When Van Leeuwen (1982) experienced a student bursting into her office and commenting about psychology it served as an emotionally powerful support for her beliefs. When Kilpatrick (1983) heard Erich Fromm's name mentioned in church and noted a renewed interest in the sermon it supported his claim that psychology was replacing religion. But we need to recognize that both of these incidents may be isolated and atypical. The power of the personal experience cannot be denied, yet the limits must also be noted.

Researchers have documented this tendency for people to overgeneralize as a result of a single vivid incident (e.g., Hamill, Wilson,
\& Nisbett, 1980). This so-called "vividness effect" tends to invalidate statistical evidence with a single example. Normally a single example would have little statistical or logical importance, but if the case is particularly vivid in your mind then it assumes an importance and influence in your thinking that is out of proportion. It is understandable then, that Kilpatrick (1983) and Van Leeuwen (1982) would be so powerfully influenced by their personal experiences. Kilpatrick seems particularly dominated by his subjective, vivid experiences and these permeate his writings about psychology. It is disturbing to realize that he is passing these vivid examples on to his readers through books and articles which may be having a disproportionate influence on Christians considering psychological services or careers in psychology.

We do not doubt the authenticity of the experiences of Kilpatrick (1983) and Van Leeuwen (1982), but in addition to our concern about overgeneralization, we cannot help but wonder if any others present perceived the event in the same way? Did others in the congregation note the same increase in interest that Kilpatrick noted upon the mention of Erich Fromm? Or was it just that Kilpatrick's awareness level was increased by the mention of a fellow psychologist? Did others present at the suicide described by Van Leeuwen feel it was "just another psychology experiment," and did they hesitate to call for help? Certainly other anti-psychologists would tend to accept this as further proof of psychology's negative effect, but is it really reliable? The power of the personal experience tends to induce intellectual egocentrism, making it difficult to recognize that others may not have reacted the same way, or have perceived the same thing, as yourself.

Scientific psychology is certainly not immune to problems of subjective bias. The picture of psychology as a completely objective, carefully reasoned experimental science has been successfully questioned by a variety of psychologists, historians, and philosophers, including Kuhn (1970) and Lakatos (1970). In addition, the "halo effect," a tendency to generalize based on one positive quality, and 
the "experimenter bias effect," the tendency to distort research results to match your hypotheses, are among the recognized subjective influences in psychology. But there are two critical differences between empirical psychology and the non-empirical approach suggested by Van Leeuwen $(1982,1985)$ and Kilpatrick (1983, 1985). First, scientific psychology has developed methodologies to control for these recognized problems of subjective bias. But in the anti-empirical world of psychology's critics no such methodologies exist and subjective bias abounds. With the scientific method, the use of control groups, blind and double blind procedures, replication, and so forth, all can help limit subjective bias. No similar controls are possible in nonempirical approaches. The second difference between empirical and subjective approaches to psychology is that an empirical psychology must ultimately face the test of public verification. Kilpatrick's subjective view operates within his personal reality, a reality that many or few may share depending on their personal experiences. Findings from empirical psychology, however, must be publically demonstrable and verifiable. In the development of psychology, the scientific method was adopted as a unique approach to the questions of philosophy and as a way out of the trap of subjectivism.

\section{Should We Humanize Psychology's Methods?}

According to the critics, psychology's methodological problems can be solved by humanizing psychology. In writing about this movement, Van Leeuwen (1985) says:

Human actions, they say, cannot be understood merely by observation and description from an outsider's point of view.... Consequently methods are needed that will enable the scientist to understand, in active cooperation with the subjects, how the subjects see their particular situation. (pp. 73-74)

Another vocal advocate of a human psychology, Kirk Farnsworth (1985), also favors getting the "inside view" through a more subjective approach to research. He would relabel the subject in an experiment a "co-investigator" and believes that the goal of research should be to "use the subjectivity of the co-investigator rather than try to control it" (p. 38).

Attempts to get the psychological inside view can be traced back to psychology's beginning and the use of the "introspective method," and is certainly not a new innovation. In fact, the inside view is valued in psychology and is solicited through various empirically derived self-report scales. There are limits on the usefulness of the inside view, however, even if it is approached systematically. Hebb (1974), in reflecting on the push within psychology to become a more "human" science, points out that many of the early founders of psychology, like Kulpe, Wundt, and Titchener, took a subjective approach to psychology and used introspection to get the inside view. In comparing the contributions of the early introspectionists to other psychologists who took an objective approach, such as Kohler, Lewin, and Harlow, Hebb asks "what is there to cite as a contribution from the subjective method that can be put beside their work?" (p. 74). Even contemporary psychologists who advocate a role for introspective methods recognize the problems. Lieberman (1979), in recommending a limited return to the use of introspection, noted that "introspection is limited not only in its scope . . . but in its accuracy. In some cases, this may be because of the subjects' limited ability to discriminate among internal states; in others, because of forgetting or even dishonesty" ( $p$. 332). Empirical methodologies can only be as reliable as the information source, and subjective experience is notably unreliable. While it is recognized that scientific methods cannot completely eliminate the problem of subjectivism, procedures have been developed for minimizing its influence. Abandoning or significantly modifying these procedures would be counterproductive unless the new methods can deal with the inaccuracy of subjective observations and the problems of forgetting and dishonesty.

Van Leeuwen (1985) does not advocate a complete abandonment of the scientific method, but rather believes that we must be willing to modify our procedures to allow the person 


\section{CHRISTIAN ANTI-PSYCHOLOGY}

being studied to be more human. To illustrate the kind of research she believes psychology should be engaged in, she cites a study of adolescent values conducted by Tom Kitwood (1980). In this preferred approach, 150 adolescents were presented with 15 common "situations" that were to be discussed with the researcher. The adolescents were given the situations a day or two ahead of time and could choose which 10 of the 15 situations they would like to discuss in a "chat." Each chat took about a half day to complete. In order to avoid an atmosphere of interrogation the researcher took no notes during the session. Van Leeuwen records that the interviews "demanded a great deal of concentration and imaginative understanding on the part of the researcher" (p. 252). Again, we cannot help wondering if the "imaginative understanding" of another researcher would have produced different results, especially since the researcher recorded no data during approximately 600 hours of interviews. Van Leeuwen's description of this study suggests a method allowing the subjects to carefully prepare their responses and encouraging the researcher to interpret their responses rather than gather data. It seems likely that, rather than actually studying the values of adolescents, the researcher recorded his own interpretation of what adolescents want researchers to believe their values are.

In this more human approach even the attempts to validate the findings are subjective. In order to determine whether his subjects were telling the truth during the interviews, Kitwood (1980) simply asked them. Van Leeuwen (1985) writes that followup letters "confirmed both the methodological and ethical success of Kitwood's approach. The participants uniformly stated that they had spoken of their experiences in a sincere and spontaneous manner-often surprising themselves in the process" (pp. 251-253). One wonders how "spontaneous" the responses were when they could select the topics they wished to discuss and had as much as two days to prepare for the interview. It would also be of interest to know whether the participants would also confirm that what Kitwood recorded through his "imaginative understanding" was truly representative of their values.

We can accept this type of research within a broad definition of empiricism, but generalizations from these results would have to be severely limited due to the subjectivism introduced by the procedures. While Van Leeuwen (1982) correctly points out that rigorously controlled experimentation limits generalizability, it is also true that generalization from research using the methods she advocates should be even more restricted. Kitwood's (1980) method is empirical in its basic approach, but the procedures used raise questions about the authenticity of the responses, the accuracy of Kitwood's imaginative interpretation of those responses, and the validation procedures used. Studies like these may provide information which traditional methods do not, but they certainly do not improve generalizability.

\section{On the Morality of Scientific Methods}

Van Leeuwen (1982) has questioned the morality of the scientific method because of the necessity of using deception in certain kinds of research, and implies this is a particularly Christian concern. Similarly, Farnsworth (1985) expresses concern about the "possible harm from deception" and writes that psychologists need to stop "lying" (p. 25). We, too, are concerned with the moral dilemma created by the necessary use of deception and with researchers who step beyond the ethical boundaries when using deception. We contend, however, that unintentional deception is often a hidden part of the alternative methods the critics advocate. The lack of control inherent in the methods of "humanized research" greatly increases the probability that the results could have been a product of any number of uncontrolled variables. The non-empirical researcher is simply more vulnerable to self-deception. Experimentalists are at least conscious of their deception and use "debriefings" to disclose the true nature of the research and to deal with any discomforture that might have been created. Why then is it immoral to 
intentionally deceive a subject for the purpose of an experiment while it is not immoral to unintentionally deceive a person by presenting results which are likely to contain erroneous conclusions? While some critics find objective scientific methods unnecessarily restrictive and counterproductive, most psychologists would think it unethical to export research without first subjecting it to empirical scrutiny. Rather than scholarship hindering understanding, as Kilpatrick contends, a little scholarship could prove to be the difference between results which are exportable and results that deceive the researcher or worse, the psychological consumer.

\section{Conclusion}

In examining the conflict between Christian anti-psychologists and scientific psychology we have focused on three points of contention. The first is the difference over what is the most valuable way of knowing. While we can accept authority, intuition, and personal experience as valuable approaches to learning, we object when knowledge from these sources is presumed in some way to be superior to knowledge gained through observation, measurement, and experimentation. Each approach should be valued for what it can contribute to our understanding of what it means to be human. Christian anti-psychologists make a fundamental error when they discount psychological knowledge simply because it was obtained through scientific methods.

The second major point of contention between Christian anti-psychologists and psychology is over the methodology involved. The anti-psychologists believe that the scientific method is a sterile approach to answering the questions of psychology, since it does not take into consideration the humanness of the subject. While we are sympathetic to their concern that psychology in its scientific form will never be able to answer all the questions we have about being human, we do not believe that the methods of psychology should be abandoned or significantly modified to allow for subjectiveness in the manner they suggest. Substituting subjective approaches for objective approaches is equivalent to choosing uncontrolled error over controlled error. Objectivity continues to be a fruitful approach to psychological studies and should not be abandoned. Those who wish to look at humanity from different perspectives need only turn to other disciplines. Sociologists, anthropologists, theologians, and creative writers all contribute to our understanding.

Finally, Christian critics of psychology have accused psychology of immorality because of the deception inherent in some methodology. We have tried to show that deception also exists in the approaches advocated by psychology's critics but in an uncontrolled and often hidden form. It could be argued that deception in any form is immoral but it seems inappropriate to argue that one kind of deception is in some way better than another. Psychologists recognize the moral dilemma created by the necessity of deception in research, have wrestled with the issues, and have attempted to devise guidelines for dealing with it. Advocates of a more subjective methodology need to recognize the self-deception that can occur as a result of the procedures they use in gathering and interpreting data, and the moral dilemma created when trying to generalize from their subjective world.

\section{REFERENCES}

Bartz, P. (1986, February). The failure of modern psychology. Bible-Science Newsletter, pp. 1-2, 5. (Available from the Bible Science Newsletter, 2911 East 42nd Street, Minneapolis, MN 55406)

Billheimer, P. (1977). Don't waste your sorrows. Fort Washington, PA: Christian Literature Crusade.

Breshears, G., \& Larzelere. R. (1981). The authority of scripture and the unity of revelation: $A$ response to $C r a b b$. Journal of Psychology and Theology, 9, 312-317.

Crabb, L. (1981). Biblical authority and Christian psychology. Journal of Psychology and Theology, 9, 305-311.

Farnsworth, K. (1985). Whole hearted integration: Harmonizing psychology and Christianity through word and deed. Grand Rapids: Baker Books.

Foster, J. (1984). North American psychology revisited. Christian Scholar's Review, 13, 240-248.

Hamill, R., Wilson, T., \& Nisbett, R (1980). Insensi- 


\section{CHRISTIAN ANTI-PSYCHOLOGY}

tivity to sample bias: Generalizing from atypical cases. Joumal of Personality and Social Psychology, 39, 578589.

Hebb, D. (1974). What psychology is about. American Psychologist, 29, 71-79.

Kitwood, T. (1980). Disclosures to a stranger. Adolescent values in an advanced industrial society. London: Routledge and Kegan Paul.

Kilpatrick, W. (1983). Psychological seduction: The failure of modern psychology. Nashville: Thomas Nelson.

Kilpatrick, W. (1985). The emperor's new clothes: The naked truth about the new psychology. Westchester, IL: Crossway Books.

Kuhn, T. (1970). The structure of scientific revolutions (enlarged ed.). Chicago: University of Chicago Press.

LaHaye, T. (1980). The battle for the mind Old Tappan, NJ: Revell

Lakatos, I. (1970). Criticism and the methodology of scientific research programmes. In I. Lakatos \& A. Musgrave (Eds.), Criticism and the growth of knowledge. Cambridge, England: Cambridge University Press.

Leahey, T. (1980). A history of psychology. Englewood Cliffs, NJ: Prentice Hall.

Lieberman, D. (1979). Behaviorism and the mind: A (limited) call for a return to introspection. American Psychologist, 34, 319-333.

Pearcey, N. (1986, February). Sensible psychologyhow creation makes the difference. Bible Science News-. letter, pp. 7-8. (Available from the Bible Science Newsletter, 2911 East 42nd Street, Minneapolis, MN 55406)
Smith, C. (1975). What part hath psychology in theology? Journal of Psychology and Theology, 3, 272-276.

Thorn, I. (1986, February). The failure of modern psychology. Bible Science Newsletter, pp. 1, 5-6. (Available from the Bible Science Newsletter, 2911 East 42nd Street, Minneapolis, MN 55406)

Van Leeuwen, M. (1982). The unfufilled (sic) apprenticeship of North American psychology. Christian Scholar's Review, 11, 291-315.

Van Leeuwen, M. (1985). The person in psychology: A contemporary Christian appraisal Grand Rapids, MI: Eerdmans.

Vitz, P. (1977). Psychology as religion: The cult of self worship. Grand Rapids, MI: Eerdmans.

Yeats, J. (1984). In support of psychology's apprenticeship. Christian Scholar's Review, 13, 236-239.

\section{AUTHORS}

FOSTER, JAMES D. Address: Department of Psychology, George Fox College, Newberg, Oregon 97132. Title: Associate Professor. Degrees: MA, PhD, The Ohio State University. Specializations: Developmental and educational psychology, psychology and religion.

LEDBETTER, MARK F. Address: Department of Psychology, Western Conservative Baptist Seminary, 5511 S.E. Hawthorne, Portland, Oregon 97215. Title: Graduate Assistant and graduate student in psychology. Degree: BA, California State University. Specialization: Clinical psychology, psychology and religion. 


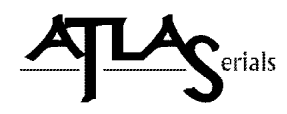

Copyright and Use:

As an ATLAS user, you may print, download, or send articles for individual use according to fair use as defined by U.S. and international copyright law and as otherwise authorized under your respective ATLAS subscriber agreement.

No content may be copied or emailed to multiple sites or publicly posted without the copyright holder(s)' express written permission. Any use, decompiling, reproduction, or distribution of this journal in excess of fair use provisions may be a violation of copyright law.

This journal is made available to you through the ATLAS collection with permission from the copyright holder(s). The copyright holder for an entire issue of a journal typically is the journal owner, who also may own the copyright in each article. However, for certain articles, the author of the article may maintain the copyright in the article. Please contact the copyright holder(s) to request permission to use an article or specific work for any use not covered by the fair use provisions of the copyright laws or covered by your respective ATLAS subscriber agreement. For information regarding the copyright holder(s), please refer to the copyright information in the journal, if available, or contact ATLA to request contact information for the copyright holder(s).

About ATLAS:

The ATLA Serials (ATLAS $®$ ) collection contains electronic versions of previously published religion and theology journals reproduced with permission. The ATLAS collection is owned and managed by the American Theological Library Association (ATLA) and received initial funding from Lilly Endowment Inc.

The design and final form of this electronic document is the property of the American Theological Library Association. 